\title{
Perception on Early Antenatal Booking by Women Attending Clinic in the Western Region in The Gambia
}

Rachel Mendy ${ }^{*}$, Veronica $\mathrm{Njie}^{2}$ and Jainaba Sey Sawo ${ }^{1}$

${ }^{1}$ University of The Gambia, MDI Road, Kanifing P.O. Box 3031, Serrekunda, The Gambia

${ }^{2}$ Department of Organizational Systems and Adult Health, School of Nursing, University of Maryland, United States

\section{Abstract}

Background: Antenatal care (ANC) services are primarily concerned with the prevention, early diagnosis and treatment of pregnancy associated health disorders. Therefore, the aim of this study was to explore perceptions of early ANC access among pregnant women in Western Region 1, The Gambia.

Methods: The study uses a qualitative phenomenological design and was conducted at the Sukuta and Serekunda health centers. The study population consisted of nineteen pregnant women who received ANC services at these facilities and were purposively selected. An interview guide of ten open ended questions was developed by the researcher. Data was collected through in depth interviews. These were audio recorded and later transcribed verbatim. Ethical approval was granted by The Gambia Government-MRC joint Ethical Committee and study participants. Thematic data analyzes was done manually.

Results: Out of the study sample, almost all the women indicated that the ideal timing to initiating care before 20 week, but only five of these women initiated early ANC registration. The following six (6) themes were identified: (a) perceived notion of early ANC; (b) need help to prevent complications; (c) perceived barriers to early ANC services; (d) perceived risk for late ANC booking (e) strategies to facilitate early ANC and (f) perception on provider/client relationship.

Conclusion: Though the women seem to have a positive perception about early booking into antenatal care, there is a critical need to strengthen health education of women on the benefits of early initiating to ANC services. The educational sessions should include family and community participation in order to deal with the barriers that affect early booking.

\section{Publication History:}

Received: July 16, 2018

Accepted: September 05, 2018

Published: September 07, 2018

\section{Keywords:}

Perceptions, Early Antenatal Booking, Pregnant women, Western Health Region 1, The Gambia

\section{Introduction}

Early booking or registering into antenatal care is important in order to detect and treat pregnancy- related complications and increase positive patient outcomes. When women book early into antenatal care, it makes it feasible for accurate estimation of gestational age [1]. Early booking is when a pregnant woman accesses antenatal care (ANC) before 20 weeks of gestation. The World Health Organisation (WHO) recommends that women should access ANC as soon as they realise that they are pregnant and this should be before five months of gestation [2,3]. Late booking means that women may not have the opportunity to benefit from screening tests, antenatal education and health advice, or supported decision-making regarding the place and choice of delivery [1]. Late booking has been linked to increased infant and maternal morbidity and mortality.

Globally, women who do not utilize antenatal care services are about 45 million; and in sub-Saharan Africa, $68 \%$ of women reported at least one antenatal visit [3]. Antenatal care is a key strategy to improving maternal and infant health globally. However, data from a survey done in sub-Saharan Africa showed that women often initiate ANC late; therefore they fail to meet the recommended number of ANC visits [4].

However, very limited studies have been found that qualitatively explored the perception of pregnant women on antenatal booking which is the focus of this study. In the Gambia, a study conducted on maternal mortality [5] revealed three delays in seeking health care. These delays are: (a) delay in decision making; (b) delay on the way due to lack of transportation and poor road networks; and (c) delay at clinic facility in instituting care service.
In order to fully understand women's experiences and perceptions of antenatal booking a qualitative study design investigating early ANC booking was conducted. This study was critical in generating preliminary data to help improve maternal health outcomes consistent with the Sustainable Development Goal number five which aims to improve maternal health.

Delayed antenatal care booking is still common amongst women in developing countries even though there are advantages in early booking as revealed by several studies from researchers in Africa [6]. For example in South Africa, although ANC coverage is high (97\%), late booking remains a challenge. In 2007 a study conducted in Tanzania revealed that between the years 2006 and 2008, the number of women who booked later than the first five months ( 20 weeks) rose from $53 \%$ to $56 \%$ substantiating the need to address this important issue.

There are limited research studies explicating reasons for early or late entry into antenatal care services among women in The Gambia. Therefore, this study was conducted to increase our knowledge and understanding of the contributory factors related to late booking for ANC by women to inform the design and implementation of

"Corresponding Author: Mrs. Rachel Mendy, University of The Gambia, MDI Road, Kanifing P. O. Box 3031, Serrekunda, The Gambia, Tel.+220 9911687/3650052 E-mail: rmendy@utg.edu.gm

Citation: Mendy R, Njie V, Sawo JS (2018) Perception on Early Antenatal Booking by Women Attending Clinic in the Western Region in The Gambia. Int J Nurs Clin Pract 5: 294. doi: https://doi.org/10.15344/2394-4978/2018/294

Copyright: (c) 2018 Mendy et al. This is an open-access article distributed under the terms of the Creative Commons Attribution License, which permits unrestricted use, distribution, and reproduction in any medium, provided the original author and source are credited. 
effective interventions to address this critical public health issue. Early booking to antenatal care services by Gambian women allows for physiological, psychological and cultural issues or concerns to be addressed. Additionally, maternal fetal well-being and the overall pregnancy status of the woman are monitored [7].

Maternal Mortality Ratio (MMR) in The Gambia is at an unacceptably high rate of 433/100,000 Live Births [8]. This study explore and examine factors important in early ANC booking from the perspectives of women that utilized the services. Data generated could help inform nurse midwives and gynaecologists about target variables that are important in facilitating early ANC services. This study could potentially help minimize maternal and child mortality rates resulting from late bookings, and thus improve outcomes for Gambian women.

\section{Aim of Study}

The aim of this study was to explore perceptions of antenatal women towards early ANC access at two public health facilities within Western Region 1 (WHR1), The Gambia.

\section{Research Objectives}

1. To explore the perceptions of early antenatal booking by pregnant women in WHR1.

2. To identify barriers and facilitating factors to early antenatal care services by pregnant women.

\section{Material and Methods}

\section{Study design}

A phenomenological qualitative study design was used. This method was used to describe a "lived experience" of a phenomenon by individuals. The rationale for choosing a phenomenological qualitative study design was because it is the appropriate method in exploring behaviour of individuals.

Setting: The study was conducted at Sukuta and Serrekunda health center both located within the Western Region One, The Gambia, A purposive selection of these two facilities was done owing to the fact that they are public health facilities where the majority of women seek antenatal care services. These facilities are located in areas that are densely populated and provide health services to a great number of women.

\section{Sample size and Sampling Techniques}

Nineteen pregnant women were purposively sampled to serve as study participants. Ten women were selected from Serrekunda Health Centre and nine women from Sukuta Health Centre.

The inclusion and exclusion criteria: Inclusion was based on (a) pregnant women (b) Coming for ANC booking (c) Women of Gambian nationality and (d) living in the study area for the past six months, while exclusion was based on (a) Women unable to complete the interviews and study instruments due to cognitive problems (b) Non-Gambian women living in the study area for the past six months, (c) Gambian women not living in the study area in the past six months and (d) women who are not pregnant.
Tools: An interview guide was used to the collect data. It consisted of ten (10) open-ended questions which allow for probing in order to get more responses from the women. The tool was divided into two parts. The first part consisted of demographic data and the second part covers women's perceptions, feelings, experiences, barriers and facilitating factors to early booking.

Validity and reliability: The tool was reviewed by the principal supervisor of the study prior to being pre-tested in Faji-kunda Health Centre in Kombo North with the same population characteristics as the study areas, Serrekunda and Sukuta Health Centres. The tool was pretested using ten (10) participants. On the basis of the pretest, changes were made in the tool.

\section{Data collection procedures}

To ensure accurate, complete and reliable data, two nurse-midwives were trained as data collectors for a day. Data were collected through in-depth interview using an interview guide at the antenatal clinics of the study areas. The interviews were tape-recorded and they lasted approximately 60 minutes from January 2014 to February 2014. The investigator provided probe questions to direct and allow the participants to tell their stories focusing on the phenomenon. Participants were informed that they would be contacted if more information was needed during the data analysis period. The participants were provided with snacks and beverages as an incentive to complete the interview. Interview data were kept separate from the consent forms to maintain participant confidentiality.

\section{Data analysis}

All data were first listened to over and over and then transcribed before analysis. Interview data were manually transcribed by the investigator. Data were analyzed using Giorgi's qualitative phenomenological analytic method which uses four steps: (a) Data were read and a general picture of the phenomenon was identified, (b) The transcripts were re-read with the research delineating meaning and focusing on the research objective of women's access to ANC, (c) The researcher reflected on the meanings and placed them into categories that had similar patterns and conceptualizing the themes (d) Conceptualized themes are then named. This was performed in an iterative process. As data were analyzed, when interviews were unclear, the researcher returned to the participants for clarification.

\section{Ethical consideration}

Approval was obtained from The Regional Health TeamWestern Region and The Gambia Government-MRC joint Ethical Committee. Consent of participants was sought and obtained both orally and written. The participants' right to privacy, anonymity and confidentiality were maintained.

\section{Results}

\section{Demographic characteristics of respondents}

The study participants consisted of nineteen women. The mean age was 30.3 years $(S D=5.26)$ ranging from $15-44$. The women's parity ranged from $1-7$ and median parity was 3 . Majority $(n=52.6 \%)$ of the participants had no formal education. Most were married, from the Mandinka tribe $(n=42.1 \%)$ and employed $(n=52.6 \%)$. All the participants were Muslims. Refer to table 1 for details. 


\begin{tabular}{|c|c|c|c|c|}
\hline Variables & Number & Mean & SD & Percentage \\
\hline \multicolumn{5}{|l|}{ Age (years) } \\
\hline $15-24$ & 3 & \multirow{4}{*}{30.6} & \multirow{4}{*}{5.26} & 15.8 \\
\hline $25-34$ & 8 & & & 42.1 \\
\hline $35-44$ & 8 & & & 42.1 \\
\hline $45 \&$ above & 0 & & & 0 \\
\hline \multicolumn{5}{|l|}{ Parity } \\
\hline 0 & 1 & \multirow{6}{*}{3.2} & \multirow{6}{*}{1.3} & 5.3 \\
\hline 1 & 3 & & & 15.8 \\
\hline 2 & 4 & & & 21.0 \\
\hline 3 & 7 & & & 36.8 \\
\hline 4 & 1 & & & 5.3 \\
\hline \multirow[t]{2}{*}{5 \&above } & 3 & & & 15.8 \\
\hline & & Mean & SD & \\
\hline \multicolumn{5}{|l|}{ Level of education } \\
\hline None & 10 & \multirow{3}{*}{4.8} & \multirow{3}{*}{$2 . .8$} & 52.6 \\
\hline $1-12$ years & 9 & & & 47.4 \\
\hline Above 12years & 0 & & & 0 \\
\hline \multicolumn{5}{|l|}{ Marital status } \\
\hline Married & 18 & & & 94.7 \\
\hline Single & 1 & & & 5.3 \\
\hline Others & 0 & & & 0 \\
\hline $\begin{array}{l}\text { Employment status } \\
\text { Unemployed }\end{array}$ & 9 & & & 47.4 \\
\hline Employed & 10 & & & 52.6 \\
\hline \multicolumn{5}{|l|}{ Ethnicity } \\
\hline Mandinka & 8 & & & 42.1 \\
\hline Jola & 2 & & & 10.5 \\
\hline Fula & 3 & & & 15.8 \\
\hline Serrere & 1 & & & 5.3 \\
\hline Wollof & 5 & & & 26.3 \\
\hline Others & 0 & & & 0 \\
\hline
\end{tabular}

Themes

\section{Theme 1: Perceived notion of early ANC}

Almost all the women said that the ideal timing for early ANC booking is between one to four months of gestation so as to enable them to get the care needed. These are some of the responses.

"The best time to join for ANC is 3-4 months so that you are checked early to know whether the baby is lying correctly (" $n$ dax haleh bi munge teda bu bax") and when time comes to give birth you will not be tired. Also the mother's blood is tested and if [it is] low you are given treatment" [participant 8 from Sukuta (SU8)].

"It is all right to join at 1month because joining early will help you." [participant 2 from sserekunda (SK2)].

One of them said that it is all right to register at five to six months gestation and it is her individual perception that at this time the woman would have been carrying a viable fetus. As she said:

Int J Nurs Clin Pract ISSN: 2394-4978
"To me, a woman should join for ANC when she is 5-6 months pregnant. But some will say that if you are 4 months you can join. I say 5-6 months because this time the baby will be big enough and start kicking and moving and at this time the baby has turned into a human being"(SK5).

Sometimes women are with the perception that they are not sick and there is no need to seek care. Therefore, they wait until they are sick that's the time they join ANC. As some women explained:

"My previous pregnancies, I joined antenatal care at 2-3 months. The reason why am coming late this time is that, I felt I am not sick and nothing is absolutely wrong with me. That is why I waited until I am 5 months plus before coming to register for ANC" (SK3).

\section{Theme 2: Women's perceived barriers to early ANC services}

Participants also identified barriers to early booking. These barriers included financial constraints to pay for transportation, and to get an antenatal card. If women do not have a national identity card, they will need to pay a fee for a non-Gambian, because there is no documentation to indicate their Gambian status. Therefore, some of the women felt that this was one of the barriers. As some of them attested.

"Money for fare to the clinic is sometimes a problem especially when I have a lot of needs and have to see which one to do first. So that might prevent me from joining early" (SU5).

Another barrier was that women said that they were unaware that they were pregnant that is why they were booking late. It was also revealed that women had the misconception that if they did not menstruate whilst breast feeding, they could not get pregnant. Given this misconception, the women reported booking late. As one of them stated that:

"I did not know that I was pregnant because for my previous child, I did not see my period until I stopped breast-feeding. I thought [it was] the same for this one. Not knowing that I am pregnant has prevented me from joining for care early" (SK4).

Domestic work was also noted by the women as a barrier to accessing antenatal care early. Women's domestic work included taking care of a sick family member and cooking for the family. In spite of the fact that women know how important it is to book early, these family engagements prevented them from booking early. These women reported that:

“...prevent me from joining early is my work at home. Since I took notice that I am pregnant, I had wanted to join for ANC early but ......... it coincides with my turn to cook for the family as we take turns for the man [ husband] and cooking at home"(SU4).

Travelling out of one's residential area was perceived as a barrier to early access to ANC. The women said that they travelled to Senegal (a neighboring country) and did not want to register there because when they were back in The Gambia, the nurses may treat them as nonGambians. The following quotation is what they reported:

"...I am registering late due to the fact that I was sick and travelled to Senegal. I did not register in Senegal because I don't want to be told that I have already taken the card in Senegal when I return to The Gambia I will be charged a non Gambian price. SK1). 
Employment was also given as a barrier to care for the women. It was stated that demands from their work place like going on trek (short trips outside their residential areas) prevented early registration. As she said:

"The reason that may prevent me from registering early for ANC is my work, as you can see I did not come early because I was on trek." (SU2).

\section{Theme 3: Women need help to prevent complications}

The majority of the women acknowledged that they required help from the nurses in order to prevent complications during pregnancy. They are cognizant of the fact that the help is both for mother and baby and it involves a comprehensive approach to render this help.

From this theme it seemed that malaria and anaemia was the biggest concern for the women. They described how the nurses used their knowledge and skills to determine their needs and detect complications early. Women stated that they were thoroughly checked by nurses to rule out impeding complications. Women were also sent to the laboratory for blood investigations and were given medications as prophylaxis against malaria and anaemia. Some women did mention that their blood pressures were checked as well during the visits. They attested that:

"...it means getting help for a better health for both the mother and the child in the womb... This help is given to both the mother and child. When I say help I mean you are sent to the lab to check to see if your blood is low or no[t]." (SK1).

"...they are helping us and we should help ourselves by coming early. It also means coming early to get your ANC card because it is for your future advantage and your life would not be in danger...."(SU9).

The women saw early enrollment into ANC was an avenue to obtain their well-being and that of the baby. This well-being includes both physical and psychological well being for the woman. Women said they felt at ease and confident knowing that nothing is wrong with them. With antenatal care, women became well and active to carry on with the pregnancy. Here is what they say:

“... a lot of benefits like today, I feel relieved because I was all along thinking of what might be wrong with me as I [did] not join early. I am given good care and I have confidence in myself. I also see women receiving medicines. This medicine will benefit me and the child...." (SK3).

\section{Theme 4: Women's perceived strategies to facilitate early ANC}

This theme described how women felt help should be given to women who did not register early for ANC. It was clearly stated that partnering with fathers, peers and community leaders to help disseminate information about the benefits of early ANC would be of support to the women. They said that:

“...strategies that can be put in place in order to help women join early are to give women advice about the importance of coming to join early. This advice should be given by the nurses, husbands" elderly persons and peers in the home, telling the women how important it is to join early... (SU2).
Also personal support from nurses and other health care providers helped to encourage women to register for ANC early because they have the knowledge of the importance of registering for ANC. As they stated:

"... because nurses have the knowledge and they should teach the women on how good and important it is to join antenatal care. Also at home the women should be encouraged to join antenatal care because it is very important..." (SK5).

\section{Theme 5: Women's risk for late ANC booking}

This theme captures the risks women reported that they might experience if they did not register for ANC early. Some of the women were aware of potential risks, but were not knowledgeable enough to provide exact information, whilst others were able to name a few of the risks attached to late booking. Here is what they said:

"I do hear that a pregnant woman may suffer a series of illness but I can't tell what type of illness. I only know that they maybe inactive" (SK2).

"The risks that can be placed on the mother and the baby are: The baby may die in the womb; the woman may have low blood [anemia] without knowing and sits home; the mother may have a difficult labour" (SK10).

"The mother may fall sick with malaria, HIV/AIDS, or any other sickness which can also affect the baby" (SU1).

Some ascribe the risks to the notion of God's power and control of the universe and His control of how and when people get ill. As they reported:

"... join early but what should go wrong will go wrong with both mother and baby. You can also go without joining for care and what is to happen will happen. If the will of God comes it has come. I mean we see people who join early and go to see the nurses every month but... .."(SK5).

\section{Theme 6: Women's perception of provider/client relationship}

Positive provider/client relationship has an effect on the care given to women. Women tend to understand information and appreciated the care given to them when they are treated well by the nurses. Treating women in a positive manner wins their confidence and makes them feel at ease.

Women were then able to confide in the nurses when they had problems. Health care providers who treated them positively were well appreciated. They reported that:

"... I like the way [I] am being received in a nice way. It gives me confidence. This makes me feel comfortable and relax. It makes me able to receive the advice am given very well and have confidence in the help I am given" (SK3).

Women reported that health care provider's negative attitude could send them away without getting care. They reported that they were harassed for coming late for their ANC visit without being asked what happened. They lamented that: 
"They should be patient with us because their attitude sends women away without getting their care" (SU2).

"...being harassed that you coming late and some of the nurses who will shout at you and then they will take your card and throw it at you. They will not ask why... (SK5).

\section{Discussion}

\section{sociodemograph}

Lack of employment or low income contributed to late booking amongst the women. This study reports that women prioritize their needs when it came to financial issues by putting household needs like school fees, feeding and clothing before ANC. This may be attributed to the fact that $47.4 \%$ of the study population is unemployed and a greater number of the $52.6 \%$ employed are paid wages. This finding is consistent with a study conducted in Afghanistan in 2013 by [9], who reported that the people were poor and could not buy food. Therefore, how were they expected to pay for medicines and transportation to the health facility?

\section{Themes}

Six themes were identified from the women's stories. The study reveals similarities in women's feelings, perceptions and experiences when accessing antenatal care services. It also shows that women acknowledged the need for help from the nurses because they reported that early access to care would result in the prevention of unwanted complications; thus facilitating positive pregnancy outcomes. This is in line with other studies which state that antenatal care is a preventive health care service that is used worldwide and is important for the health of pregnant women and their babies [10]. Outside the provision of medical follow-up and timely intervention as needed, antenatal care has a psychosocial benefit [10]).

Eighteen women reported that it was ideal to register for care at one to four months gestation; and one woman reported five to six months. Although the majority of the women's responses were one to four months gestation, their timing for entry into care was well after the recommended registration at fourteen weeks of gestation. The explanation of the women on registering as early as one to four months gestation was that it allowed for early health care screening and detection of complications.

Regarding perceived barriers, a number of barriers were noted as obstacles to accessing early antenatal care services by the women. Financial constraints such as transportation costs; costs for antenatal care were seen as important barriers for the women. Though it has been officially announced in The Gambia that maternal and child health care is free services, there are some health care providers who charge the women for services when they do not present their identity cards, thus perpetuating late ANC booking. This finding is similar to other studies that say that, the costs of obstetrical care can be an important barrier to poor women [9]. Even when these services are officially free of charge, hidden costs due to corruption may add up to a substantial amount [9].

It was clearly indicated by women in this study that lack of fares for transportation is a barrier for them to register early. The cost attached to taxi and bus fares prevented women from going for ANC visits and even when fares were at a low rate, women who lived in extreme poverty could not afford to pay [11].
Domestic engagements were shown in the study to have an impact on women's antenatal care seeking. Traditionally, women are the caretakers of the home and sick family members. As shown in this study women said that they had to take care of a sick mother -inlaw. Additionally, the issue of polygamy and sharing domestic duties was another barrier. This had an impact on being unaware when the women were pregnant and needed to start ANC. Further, travelling out of their residential areas and employment commitments has led to late booking amongst the women. Findings are similar to a study conducted in south-east Tanzania by [12] who noted that women's reasons for not registering early were; not recognizing the pregnancy early; not being able to come due to illness or other obligations such as travelling, caring for a sick person or agricultural work.

Women felt that they could not register for ANC services elsewhere when they travelled out of their residential areas, especially outside the Gambia, in order to avoid being harassed by the nurses and treated as non-Gambians. Women had the misconception that when one is breastfeeding they cannot get pregnant which has led to late registration for care and in some instances women waited until they were ill to join. Thus, there is a need for education to inform and clarify misconceptions so as to promote early booking into ANC.

Interestingly, women reported that they did not need to register for ANC if they were not sick. This misconception could lead to devastating situations because women may feel that they are not ill and would not seek care early whilst they will be developing complications without their knowing. A study in 2011 by [13] also found that women believed that pregnancy was not a disease but a normal life phenomenon and did not value seeking care early.

Nurses were perceived by the women as experts that could determine their needs and help detect impeding complications. Malaria and anaemia were shown to be the biggest concern for the women. They reported that with ANC the nurses took their time to examine and send them to the laboratory for blood test. The majority of the women knew that when they were sent to the laboratory, their blood was investigated for malaria, and anaemia; and they were given prophylaxis to prevent complications. Few of the women mentioned that the blood taken from them was also tested for HIV. They also mentioned that nurses would provide them with information on how to use protective measures to prevent HIV. If positive, they were started on antiretroviral medications.

Women's perception of early registration into ANC showed that when one registers early for care, it means well-being for both mother and baby. This is achieved through the routine screening during antenatal care services. The mother gains well-being both physically and psychologically because the women said that they felt at ease and confident knowing that nothing is wrong with them. Thus there was a reduction in stress for the women.

A study conducted noted that antenatal care is used globally as a preventive health care service and has been seen to be of importance to the health of pregnant women and their babies. Besides medical follow-up and prompt interventions, antenatal care has some psychological benefits [10].

The study has practice implications in that strategies could be used to encourage women to initiate ANC early. A greater number of the participants attested that health education should be provided to the 
women in order to get them to register for ANC early. This should be in the form of personal assistance from health care providers because they feel that the care providers have knowledge of health matters and information given will be taken seriously. Also, partnering with fathers, peers and community leaders is vital because with community involvement, there is a sense of ownership. Thus extra effort is put in to make sure that women register early and benefit from care as early as possible so as not to miss important care. This report is consistent with a study conducted in a hospital in Kampala, Uganda in 2013 by [14] and colleagues who reported that "health education on the timing and importance of attending antenatal care early should be done in the communities where women and other people that influence the pregnant woman's decision to attend antenatal care lives so that they get this information even before they conceive. This can be done through the media, places of worship, schools and community gatherings" The study throws light on the risks women are exposed to when they do not register early or do not register at all. Some of the women were aware of potential risks, but were not knowledgeable to provide exact information. High blood pressure, preterm delivery, difficult labour and death of both mother and baby were other risks that the participants identified.

Some of the women perceived HIV/AIDS as a risk that could be encountered when ANC is not sought early. This is a misconception held by women and needs to be clarified because late access to ANC does not place women at risk of contracting HIV. However, if women are infected with the virus, and do not know their status there is a likelihood of transmitting it to the unborn child. Some attributed the risks to the notion of God's power and control of the universe and that he has the will power and control of how and when people get well or ill. Women indicated that no matter what one does to prevent themselves against mishaps like ailments and complications during pregnancy, the will of God takes its own course.

The women affirmed that they appreciated when they were given a positive treatment by the nurses. This gave them confidence and they were able to confide in the nurses when they had problems. Hence ANC provided an avenue for information giving, establishing a positive provider/client relationship that brought about great understanding of whatever the women were experiencing.

Unpleasant nurses' attitudes were reported by the women. They said that though not all nurses behaved negatively towards the women during ANC, a number of the nurses were "arrogant and they harassed" the women for coming late for antenatal visits. The nurses did not take the extra effort to find out what problems the women might have that led to their coming late. Women reported that there were instances they are shouted at when they asked questions or their antenatal cards were thrown back at them and were asked to come back at a later date for ANC care. Nurses' unprofessional behaviours and negative attitudes were reported by other studies [9]. Findings from [13] noted that women were being judged for coming late to the clinic. Such acts from nurses demoralized women preventing them from sharing their concerns with the nurses. Some of the women are also concerned with nurses multitasking when attending to them. For example, they reported that nurses chatted whilst carrying out a procedure on them or left them in the middle of a procedure to attend to other issues. Concerns about delay in receiving laboratory test results were raised by some of the women.

\section{Conclusion}

The study generated preliminary data on antenatal women's feelings, perception, and experiences during antenatal care (ANC). Women perceived ANC as an avenue where they can access care and be cared for. The study findings revealed that when a woman registers early for care, they have an opportunity to receive all the care they need, thus preventing complications and increasing well-being for mother and the unborn baby. Even though some women were able to give the correct timing for initiating antenatal care, many women still started ANC late after twenty weeks. Health education by the health care providers, family members and the community on the importance of early registration was seen as key response to get women to register early for ANC. Involving peers, husbands and religious leaders is vital as information seems to disseminate well if given by people who are trusted and held in high esteem.

\section{Acknowledgements}

A lot of efforts have been put into this for it to reach its completion stage. I would like to thank my wonderful mentor and supervisor Professor Veronica Njie-Carr for her unrelenting encouragement and Dr Francis Sarr for his fatherly guidance.

\section{Competing Interests}

The authors declare that they have no competing interests.

\section{References}

1. Baker EC, Rajasingam D (2012) Using trust database to identify predictors of late booking for antenatal care within the UK. Public Health 126: 112-116.

2. Villar J, Bergsjo P (2002) WHO antenatal cares randomize trial: WHO programme to map best reproductive health practices. Manual for the implementation of the new model.

3. World Health Organization (2003) Antenatal care in developing countries: Promises, achievements and missed opportunities. Geneva, Switzerland.

4. Pell C, Menaca A, Were F, Afrah NA, Chatio S, et al. (2013) Factors Affecting Antenatal Care Attendance: Results from Qualitative Studies in Ghana, Kenya and Malawi. PLoS ONE 8: e53747.

5. Cham M, Sundby J, Vangen S (2005) Maternal Mortality in the rural Gambia, A qualitative study on access to emergency obstetric care. Reproductive Health 2: 3 .

6. Solarin I, Black V (2012) "They Told Me to Come Back" women's Antenatal Care Booking Experience In Inner -City Johannesbury. Matern Child Health Matern Child Health Journal 15: 1067-1075

7. Littleton LY, Engebretson J (2001) Cultural negotiation: A constructivist based model for nursing practice. Nursing Outlook 49: 223-230.

8. The Gambia Bureau of Statistics (GBOS) and ICF international (2014) The Gambia Demographic and Health Survey.

9. Rahmani Z, Brekke MM (2013) Antenatal and obstetric care in Afghanistan-a qualitative study among health care receivers and health care providers. BMC Health Services Research 13: 166.

10. Beeckman K, Louckx F, Putman K (2011) Predisposing Enabling and Pregnancy-Related Determinants of Late Initiation of Prenatal Care. Matern Child Health J 15: 1067-1075.

11. Finlayson K, Downe S (2013) Why Do Women Not Use Antenatal Services in Low- and Middle-Income Countries? A Meta-Synthesis of Qualitative Studies. PLoS Med 10: e1001373.

12. Gross Alba S, Glass TR, Schellenberg JA, Obrist B (2012) Timing of antenatal care for adolescent and adult pregnant women in south-eastern Tanzania. BMC Pregnancy and Childbirth 12: 16.

13. Callaghan M, Buller AM, Murray SF (2011) Understanding 'late bookers' and their social circumstances. British journal of midwifery 19: 1. 
Citation: Mendy R, Njie V, Sawo JS (2018) Perception on Early Antenatal Booking by Women Attending Clinic in the Western Region in The Gambia. Int J Nurs Clin Pract 5: 294. doi: https://doi.org/10.15344/2394-4978/2018/294

Page 7 of 7

14. Kissuule I, Kaye DK, Najjuka F, Ssematimba SK, Arinda A, et al. (2013) Timing and reasons for coming late for the first antenatal care visit by pregnant women at Mulago hospital, Kampala Uganda. BMC Pregnancy and Childbirth 13: 121. 